\title{
RESEARCH
}

Open Access

\section{TREM2 activation attenuates neuroinflammation and neuronal apoptosis via PI3K/Akt pathway after intracerebral hemorrhage in mice}

Shengpan Chen ${ }^{1,2+}$, Jianhua Peng ${ }^{2,3+}$, Prativa Sherchan ${ }^{2}$, Yongjie Ma ${ }^{1}$, Sishi Xiang ${ }^{1}$, Feng Yan ${ }^{1}$, Hao Zhao ${ }^{1}$, Yong Jiang ${ }^{3,4}$, Ning Wang ${ }^{1}$, John $\mathrm{H}_{\text {. Zhang }}{ }^{2,5^{*}}$ and Hongqi Zhang ${ }^{1 *}$

\begin{abstract}
Background: Neuroinflammation is an important host defense response to secondary brain injury after intracerebral hemorrhage (ICH). Triggering receptor expressed on myeloid cells 2 (TREM2) confers strong neuroprotective effects by attenuating neuroinflammation in experimental ischemic stroke. Recent studies suggest that apolipoprotein $\mathrm{E}$ (apoE) is a novel, high-affinity ligand of TREM2. This study aimed to investigate the effects of TREM2 activation on neuroinflammation and neuronal apoptosis in a mouse model of $\mathrm{ICH}$.

Methods: Adult male CD1 mice $(n=216)$ were subjected to intrastriatal injection of bacterial collagenase. The TREM2 ligand, apoE-mimetic peptide COG1410 was administered intranasally at $1 \mathrm{~h}$ after ICH induction. To elucidate the underlying mechanism, TREM2 small interfering RNA (siRNA) and the phosphatidylinositol 3-kinase (PI3K) inhibitor LY294002 were administered intracerebroventricularly prior to COG1410 treatment. Neurobehavioral tests, brain water content, immunofluorescence, western blotting, and Fluoro-Jade C- and terminal deoxynucleotidyl transferase dUTP nick end labeling staining were performed.
\end{abstract}

(Continued on next page)

\footnotetext{
*Correspondence: johnzhang3910@yahoo.com; xwzhanghq@163.com

†Shengpan Chen and Jianhua Peng contributed equally to this work.

2Department of Physiology and Pharmacology, Department of Neurosurgery

and Anesthesiology, School of Medicine, Loma Linda University, Risley Hall,

Room 219, 11041 Campus Street, Loma Linda, CA 92354, USA

'Department of Neurosurgery, Xuanwu Hospital, Capital Medical University,

China International Neuroscience Institute (China-INI), No. 45 Changchun

Street, Xicheng District, Beijing 10053, China

Full list of author information is available at the end of the article
}

(C) The Author(s). 2020 Open Access This article is licensed under a Creative Commons Attribution 4.0 International License, which permits use, sharing, adaptation, distribution and reproduction in any medium or format, as long as you give appropriate credit to the original author(s) and the source, provide a link to the Creative Commons licence, and indicate if changes were made. The images or other third party material in this article are included in the article's Creative Commons licence, unless indicated otherwise in a credit line to the material. If material is not included in the article's Creative Commons licence and your intended use is not permitted by statutory regulation or exceeds the permitted use, you will need to obtain permission directly from the copyright holder. To view a copy of this licence, visit http://creativecommons.org/licenses/by/4.0/ The Creative Commons Public Domain Dedication waiver (http://creativecommons.org/publicdomain/zero/1.0/) applies to the data made available in this article, unless otherwise stated in a credit line to the data. 


\begin{abstract}
(Continued from previous page)
Results: Endogenous TREM2 expression was increased and peaked at $24 \mathrm{~h}$ after ICH. TREM2 was expressed on microglia, astrocytes, and neurons. COG1410 improved both short-term and long-term neurological functions, reduced brain edema, inhibited microglia/macrophage activation and neutrophil infiltration, and suppressed neuronal apoptotic cell death in perihematomal areas after $\mathrm{ICH}$. Knockdown of endogenous TREM2 by TREM2 siRNA aggravated neurological deficits and decreased the expression of TREM2 in naïve and ICH mice. COG1410 was associated with upregulation of TREM2, PI3K, phosphorylated-Akt, and BCl-2 and downregulation of TNF- $a, I L-1 \beta$, and Bax after ICH. The neuroprotective effects of COG1410 were abolished by both TREM2 siRNA and PI3K inhibitor LY294002.

Conclusions: Our finding demonstrated that TREM2 activation improved neurological functions and attenuated neuroinflammation and neuronal apoptosis after $\mathrm{ICH}$, which was, at least in part, mediated by activation of PI3K/Akt signaling pathway. Therefore, activation of TREM2 may be a potential therapeutic strategy for the management of $\mathrm{ICH}$ patients.
\end{abstract}

Keywords: Intracerebral hemorrhage, TREM2, ApoE, Neuroinflammation, Apoptosis

\section{Background}

Intracerebral hemorrhage $(\mathrm{ICH})$ is a common and severe cerebrovascular disease accounting for approximately 15 to $20 \%$ of all strokes, with high rates of mortality and morbidity [1]. The formation of hematoma and mechanical damage to adjacent tissues after sudden rupture of cerebral blood vessels results in a sharp increase in intracranial pressure, which is regarded as the primary brain injury [2]. However, surgical removal of the hematoma in clinical practice targeting primary brain injury after $\mathrm{ICH}$ shows no benefit to patients and rarely affects neurological recovery [3, 4]. Red blood cell debris and blood components trigger secondary brain injury following $\mathrm{ICH}$, leading to an inflammatory response, oxidative stress, neuronal apoptosis, mitochondrial dysfunction, and blood-brain barrier (BBB) disruption [5, 6]. In recent decades, most experimental studies have focused on the mechanisms underlying $\mathrm{ICH}$-induced secondary injury in search of novel therapeutic targets for $\mathrm{ICH}$.

Neuroinflammation begins immediately after the formation of hematoma and is an important host defense response to secondary brain injury after ICH [7]. The inflammatory mechanisms include activation of microglia, the brain's resident macrophages, and recruitment of peripheral leukocytes to the perihematomal region $[5,8]$. Subsequently, activated microglia/macrophages and peripheral leukocytes release proinflammatory cytokines, including tumor necrosis factor (TNF)- $\alpha$, interleukin (IL)-1 $\beta$, chemokines, free radicals, and other toxic chemicals, which ultimately lead to brain edema, BBB disruption, and neuronal apoptosis [3, 5, 9]. $\mathrm{ICH}$-induced neuronal apoptosis results in neutrophils and leukocytes infiltration into the brain, which further aggravates inflammatory injury $[7,10]$. Therefore, anti-inflammatory treatment could provide a potential therapeutic strategy after the onset of $\mathrm{ICH}$.
Triggering receptor expressed on myeloid cells 2 (TREM2) is an important innate immune receptor, which belongs to the lectin-like immunoglobulin superfamily and is primarily expressed on myeloid cells, such as immature dendritic cells, osteoclasts, tissue macrophages, and microglia $[11,12]$. It contains an ectodomain, a transmembrane domain, and a short cytoplasmic tail [13]. TREM2 is implicated in a number of cellular processes including proliferation, survival, regulation of inflammatory cytokine production, and phagocytosis of apoptotic neuronal cells [14]. Although the precise endogenous ligand that activates TREM2 has yet to be fully characterized, recent studies suggest that apolipoprotein E (apoE) is a novel, high-affinity ligand of TREM2 [15-19]. Moreover, it has been demonstrated that overexpression of TREM2 could suppress inflammatory response in animal models of Alzheimer disease, Parkinson disease, multiple sclerosis, and other neurodegenerative diseases [20-22]. In recent years, accumulating evidence has shown that TREM2 confers strong neuroprotective effects by attenuating neuroinflammation in experimental ischemic stroke [23-26]. However, the potential neuroprotective role of TREM2 after $\mathrm{ICH}$ has yet to be elucidated.

As a lipid kinase, phosphatidylinositol 3-kinase (PI3K) can induce the phosphorylation of protein kinase $\mathrm{B}$ (Akt) to regulate cell survival, growth, and angiogenesis in response to extracellular signals [27]. Previous studies have demonstrated that PI3K/Akt signaling exerts antineuroinflammation, anti-oxidative stress, and antiapoptotic properties in neurons [28, 29]. Interestingly, recent data revealed that PI3K/Akt signaling is the downstream target of TREM2 and is involved in TREM2-mediated inflammatory responses [27, 30-33].

In the present study, we hypothesized that activation of TREM2 with an apoE-mimetic peptide, COG1410, could improve neurological outcomes and attenuate 
neuroinflammation and neuronal apoptosis by modulating PI3K/Akt signaling pathway in a mouse model of $\mathrm{ICH}$.

\section{Methods}

Animals

All experimental procedures were approved by the Institutional Animal Care and Use Committee of Loma Linda University and were performed according to the Guide for the Care and Use of Laboratory Animals of the National Institutes of Health and reported in compliance with the ARRIVE (Animal Research: Reporting of In Vivo Experiments) guidelines. A total of 216 male CD1 mice (8-week-old, weight 30-40 g; Charles River, Wilmington, MA, USA) were housed in a temperature and humidity controlled room under a standard 12-h light/dark cycle for a minimum of 3 days before $\mathrm{ICH}$ induction and provided free access to food and water.
Experimental design

In the current study, all mice were randomly assigned to the following five experimental procedures (Fig. 1) that were blinded to the researchers.

\section{Experiment 1}

To evaluate the time course of endogenous TREM2 expression in the ipsilateral/right hemisphere after ICH, 36 mice were randomly divided into six groups: sham, 3,6 , 12,24 , and $72 \mathrm{~h}$ after $\mathrm{ICH}(n=6$ /group). Western blot analysis was performed to determine the changes in TREM2 expression. An additional two mice were used for double immunofluorescence staining at $24 \mathrm{~h}$ after ICH.

\section{Experiment 2}

To determine the effects of TREM2 activation with COG1410 on neuroinflammation, brain water content and neurobehavior tests were measured at 24 and $72 \mathrm{~h}$ after ICH. For effects of the drug at $24 \mathrm{~h}$ after $\mathrm{ICH}, 30$

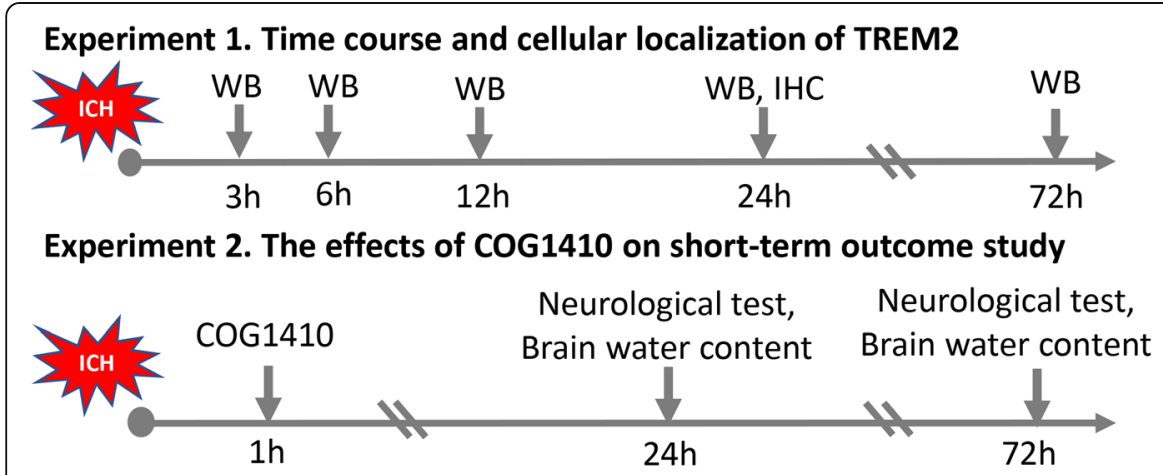

Experiment 3. The effects of COG1410 on neuroinflammation and apoptosis

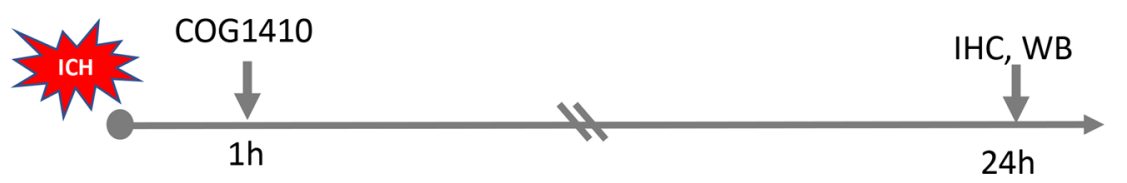

Experiment 4. The effects of COG1410 on long-term neurological functions

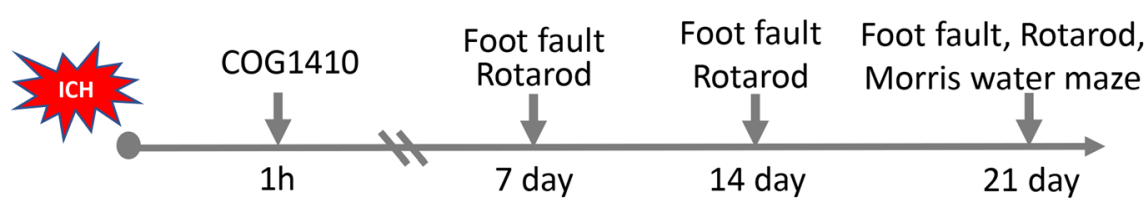

Experiment 5. TREM2 knockdown and LY294002 abolished the protective effects of COG1410

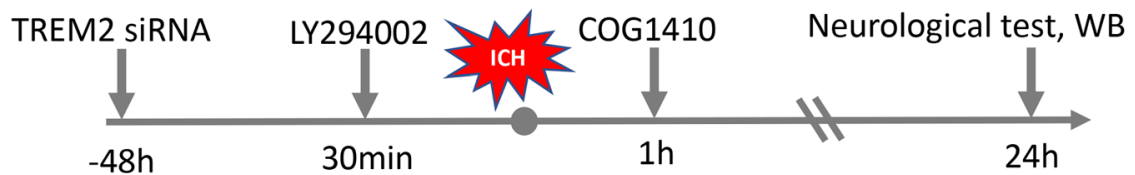

Groups:
(1)Sham
(2)ICH $3 \mathrm{~h}$
(3)ICH $6 \mathrm{~h}$
(4)ICH $12 \mathrm{~h}$
(5)ICH 24h
(6)ICH 72h
Groups:
(1)Sham
(2)ICH+Vehicle
(3)ICH+COG1410
(4)ICH+COG1410
(5)ICH+COG1410
Groups:
(1)Sham
(2)ICH+Vehicle
(3)ICH+COG1410
Groups:
(1) $\mathrm{Sham}$

$(n=6)$

$(n=6)$

$(n=6)$

$(n=6)$

$(n=8)$

$(n=6)$

$(n=12)$

$(n=12)$

$(n=6)$

$(n=12)$

$(n=6)$

$(n=12)$

$(n=12)$

$(n=12)$

$(n=8)$

$(n=8)$

(2) $\mathrm{ICH}+$ Vehicle

(3)ICH+COG1410

$(n=8)$

Groups:

(1)Naïve+scr siRNA

(2)Naïve+TREM2 siRNA

(3) ICH+scr SiRNA

(4)ICH+TREM2 SIRNA

(5)Sham*

(6) $\mathrm{ICH}+$ Vehicle*

(7) $\mathrm{ICH}+\mathrm{COG} 1410$ *

(8)ICH+COG1410+TREM2 siRNA $\quad(n=6)$

(9)ICH+COG1410+scr siRNA $\quad(n=6)$

(10) ICH+COG1410+LY294002 (n=6)

(11)ICH+COG1410+DMSO ( $\quad n=6)$

Fig. 1 Experimental design and animal groups. ICH, intracerebral hemorrhage; WB, western blot; IHC, immunohistochemistry; DMSO, dimethyl sulfoxide. Asterisk indicates samples shared with experiment 3 
mice were assigned into five groups: sham, $\mathrm{ICH}+$ vehicle, $\mathrm{ICH}+$ COG1410 $(70 \mu \mathrm{g} / \mathrm{kg}), \mathrm{ICH}+$ COG1410 $(200 \mu \mathrm{g} /$ $\mathrm{kg})$, and ICH + COG1410 (600 $\mu \mathrm{g} / \mathrm{kg})(n=6 /$ group $)$. According to brain water content and neurobehavioral tests, a dosage of COG1410 at $200 \mu \mathrm{g} / \mathrm{kg}$ had the best treatment effect. For the effects of the drug at $72 \mathrm{~h}$ after $\mathrm{ICH}, 18$ mice were randomly divided into three groups: sham, $\mathrm{ICH}$ + vehicle, and ICH + COG1410 (200 $\mu \mathrm{g} / \mathrm{kg})(n=6 /$ group $)$.

\section{Experiment 3}

To assess the effects of COG1410 administration on microglia/macrophage activation, neutrophil infiltration, and neuronal cells death at $24 \mathrm{~h}$ after ICH, 18 mice were randomly divided into three groups for immunofluorescence, Fluoro-Jade C (FJC)-, and terminal deoxynucleotidyl transferase dUTP nick end labeling (TUNEL) staining: sham, ICH + vehicle, and ICH + COG1410 $(200 \mu \mathrm{g} / \mathrm{kg})(n=6 /$ groups $)$. An additional 18 mice were randomly divided into three groups for western blot analysis: sham, ICH + vehicle, and $\mathrm{ICH}+$ COG1410 $(200 \mu \mathrm{g} / \mathrm{kg})$ ( $n=6 /$ groups $)$.

\section{Experiment 4}

To investigate the effects of COG1410 on long-term neurobehavior functions after $\mathrm{ICH}, 24$ mice were randomly assigned into three groups: sham, $\mathrm{ICH}+$ vehicle, and ICH + COG1410 (200 $\mu \mathrm{g} / \mathrm{kg})(n=8 /$ groups $)$. The foot fault test and Rotarod test were performed on days 7, 14, and 21 after $\mathrm{ICH}$. The Morris water maze was conducted on days 21-25 after ICH.

\section{Experiment 5}

To explore the underlying mechanisms of the neuroprotective role of COG1410, 42 mice were randomly divided into seven groups: sham, ICH + vehicle, ICH + COG1410 $(200 \mu \mathrm{g} / \mathrm{kg}), \mathrm{ICH}+\mathrm{COG} 1410+$ TREM2 small interfering RNA (siRNA), ICH + COG1410 + scramble siRNA (scr siRNA), ICH + COG1410 + LY294002, and ICH + COG1410 + DMSO ( $n=6$ /groups). The samples for sham, ICH + vehicle, and ICH + COG1410 groups were shared from experiment 3 , and an additional 24 mice were used for the experiment. Additionally, to verify the efficacy of TREM2 siRNA to knockdown TREM2, 24 mice were randomly divided into four groups: naïve + scr siRNA, naïve + TREM2 siRNA, ICH + scr siRNA, and ICH + TREM2 siRNA ( $n=6 /$ groups). Neurobehavioral tests and western blot analysis were performed at $24 \mathrm{~h}$ after $\mathrm{ICH}$.

\section{ICH model}

Intracerebral hemorrhage was induced by stereotacticguided injection of bacterial collagenase into the right basal ganglia as previously described [2]. Briefly, mice were anesthetized with a mixture of ketamine $(100 \mathrm{mg} / \mathrm{kg})$ and xylazine (10 mg/kg; 2:1, intraperitoneal injection) and positioned prone in a stereotaxic head frame (Kopf Instruments, Tujunga, CA, USA). An artificial tears ointment (Rugby, Livonia, MI, USA) was used to keep the eyes moist during surgery. A 1-mm cranial burr hole was drilled, and a 26-gauge needle of a 10- $\mu \mathrm{L}$ Hamilton syringe was inserted stereotactically into the right basal ganglia (coordinates $0.2 \mathrm{~mm}$ posterior, $2.2 \mathrm{~mm}$ lateral to bregma, and $3.5 \mathrm{~mm}$ below the dura). Bacterial collagenase type VII-S (0.075 units, Sigma-Aldrich, St. Louis, MO, USA) dissolved in $0.5 \mu \mathrm{L}$ sterile phosphate-buffered saline (PBS) was infused into the brain at a rate of $0.167 \mu \mathrm{L} / \mathrm{min}$ with an infusion pump (Stoelting, Harvard Apparatus, Holliston, MA, USA). After injection, the needle was left in the position for an additional $5 \mathrm{~min}$ to prevent reflux and was withdrawn slowly at a rate of $1 \mathrm{~mm} / \mathrm{min}$. The cranial burr hole was sealed with bone wax, the scalp was sutured, and $0.4 \mathrm{~mL}$ of normal saline was injected subcutaneously to avoid postsurgical dehydration. Buprenorphine $(0.03 \mathrm{mg} / \mathrm{kg}$, Sigma-Aldrich) was administered subcutaneously to relieve the post-procedural pain. Mice were allowed to recover fully under close observation. The sham operation was performed with needle insertion only.

\section{Intranasal administration}

Intranasal administration at $1 \mathrm{~h}$ after $\mathrm{ICH}$ was performed as previously described [34]. Saline or COG1410 at three different dosage $(70 \mu \mathrm{g} / \mathrm{kg}, 200 \mu \mathrm{g} / \mathrm{kg}$, and $600 \mu \mathrm{g} / \mathrm{kg})$ dissolved in saline was administered intranasally. A total volume of $20 \mu \mathrm{L}$ was delivered into the bilateral nares, alternating one naris at a time, with $5 \mu \mathrm{L}$ per naris every $5 \mathrm{~min}$ for a period of $20 \mathrm{~min}$.

\section{Intracerebroventricular injection}

Intracerebroventricular administration was performed as previously described [2]. Briefly, a 26-gauge needle of a $10-\mu \mathrm{L}$ Hamilton syringe was inserted into the left lateral ventricle through a cranial burr hole at the following coordinates relative to bregma: $0.3 \mathrm{~mm}$ posterior, $1.0 \mathrm{~mm}$ lateral, and $2.3 \mathrm{~mm}$ deep. A microinfusion pump was used for intracerebroventricular administration at a rate of $0.667 \mu \mathrm{L} / \mathrm{min}$. The needle was left in place for an additional $8 \mathrm{~min}$ after the end of infusion and then removed over 3 min period. The burr hole was sealed with bone wax. The TREM2 siRNA (100 pmol/2 $\mu \mathrm{l}$, OriGene Technologies, Rockville, MD, USA) or scr siRNA (100 pmol/ $2 \mu \mathrm{l}$, OriGene Technologies, Rockville, MD, USA) were delivered $48 \mathrm{~h}$ before ICH modeling. LY294002 (10 nmol/ $/ 2 \mathrm{l}$, Selleck Chemicals, Houston, TX, USA) or 25\% DMSO $(2 \mu \mathrm{l})$ was infused $30 \mathrm{~min}$ before $\mathrm{ICH}$ induction.

\section{Short-term neurobehavior assessment}

Short-term neurological deficits were evaluated using the modified Garcia test, corner turn test, and forelimb 
placement test by two trained investigators blinded to experimental groups at 24 and $72 \mathrm{~h}$ after $\mathrm{ICH}$, as previously described [35]. The modified Garcia test was assessed according to a 21-point score system with seven individual tests including spontaneous activity, axial sensation, vibrissae proprioception, limb symmetry, lateral turning, forelimb walking, and climbing. For the corner turn test, animals were allowed to advance into a $30^{\circ}$ angle corner and exit by turning either to the left or right. Choice of turning was recorded for a total of ten trials, and a score was calculated as number of left turns/all trials $\times 100$. For the forelimb placement test, the placement of ipsilateral forelimb on the countertop when the vibrissa was stimulated was recorded. The percent of the ipsilateral forelimb placement out of ten total trials was calculated.

\section{Brain water content measurement}

Brain edema was evaluated by measuring brain water content using wet/dry method as previously described [36]. Briefly, mice were decapitated under deep anesthesia at 24 and $72 \mathrm{~h}$ after $\mathrm{ICH}$, and the brains were immediately removed and divided into five parts: the ipsilateral and contralateral cortices, the ipsilateral and contralateral basal ganglia, and the cerebellum. Each part was immediately weighed on an electric analytic balance (APX-60, Denver Instrument, Bohemia, NY, USA) to obtain the wet weight and then dried for $24 \mathrm{~h}$ at $100^{\circ} \mathrm{C}$ to obtain the dry weight. Brain water content was calculated using the following formula: brain water content $(\%)=[($ wet weight - dry weight $) /$ wet weight $] \times 100 \%$.

\section{Long-term neurobehavior assessment}

The foot fault test and Rotarod test were performed to assess sensorimotor coordination and balance in the first, second, and third week after $\mathrm{ICH}$, whereas the Morris water maze was performed to evaluate spatial learning and memory abilities on days 21 to 25 after $\mathrm{ICH}$, as previously reported [34]. Briefly, for the foot fault tests, mice were allowed to move along a horizontal wire grid $(20 \times 100 \mathrm{~cm})$ for $2 \mathrm{~min}$ and the number of left forelimb missteps was recorded. For the Rotarod test, the rotating speed was started at 5 revolutions/min and gradually accelerated by 2 revolutions/min every $5 \mathrm{~s}$. The duration that mice were able to stay on the accelerating rotating cylinder was recorded by a photobeam circuit. For the Morris water maze, mice were placed in a semirandom set of start locations to find a visible platform above the water level in $60 \mathrm{~s}$. After, the mice were guided to stay on the platform for $5 \mathrm{~s}$ and their swim path, escape latency, and swim distance were recorded individually. On the last day, the probe trial was performed in which the platform was removed and the duration of time spent in the probe quadrant was recorded. A computerized tracking system (Noldus Ethovision, Tacoma, WA, USA) was used to record all data.

\section{Western blotting analysis}

Western blotting was performed as previously described [6]. Briefly, after brain protein sample preparation using RIPA lysis buffer (Santa Cruz Biotechnology, Santa Cruz, CA, USA), equal amounts of protein were loaded on an SDS-PAGE gel and run using electrophoresis and then transferred to a nitrocellulose membrane. The membrane was blocked and incubated overnight at $4{ }^{\circ} \mathrm{C}$ with the following primary antibodies: goat anti-TREM2 (1: 1000, Abcam, Cambridge, MA, USA), rabbit anti-PI3K (1:1000, Cell signaling, Danvers, MA, USA), rabbit antiphosphorylated Akt (p-Akt, 1:1000, Cell signaling), rabbit anti-Akt (1:1000, Cell signaling), rabbit anti-TNF$\alpha(1: 1000$, Abcam), rabbit anti-IL-1 $\beta$ (1:1000, Abcam), anti-Bcl-2 (1:2000, Abcam), anti-Bax (1:4000, Abcam), and goat anti- $\beta$-actin (1:5000, Santa Cruz Biotechnology). Appropriate secondary antibodies (1:3000, Santa Cruz; 1:5000, Abcam) were selected to incubate with the membrane for $2 \mathrm{~h}$ at room temperature. The bands were probed with an ECL Plus chemiluminescence regent Kit (Amersham Biosciences, Arlington Heights, PA, USA) and visualized with the image system (Versa Doc, model 4000, Bio-Rad, Hercules, CA, USA). Relative density of the protein immunoblot images were analyzed by ImageJ software (ImageJ 1.4, NIH, Bethesda, MD, USA).

\section{Immunofluorescence staining}

Briefly, after mice were anesthetized with isoflurane and intracardially perfused with ice-cold PBS and $10 \%$ formalin, the brains were removed, fixed in $10 \%$ formalin overnight at $4{ }^{\circ} \mathrm{C}$, and dehydrated with $30 \%$ sucrose for 3 days. Brain tissues were snap-frozen at $-80^{\circ} \mathrm{C}$ and cut into $10-\mu \mathrm{m}$ thick coronal sections using a cryostat (CM3050S; Leica Microsystems, Bannockburn, III, Germany). Immunofluorescence staining was performed as previously described [7]. Brain samples were incubated overnight at $4{ }^{\circ} \mathrm{C}$ with primary antibodies including rabbit anti-ionized calciumbinding adaptor molecule 1 (Iba-1, 1:100, Abcam), rabbit anti-glial fibrillary acidic protein (GFAP, 1:100, Abcam), rabbit anti-neuronal specific nuclear protein (NeuN, 1:200, Abcam), rabbit anti-myeloperoxidase (MPO, 1:500, Abcam), and goat anti-TREM2 (1:1000, Abcam). The sections were then incubated with corresponding secondary antibodies (1:200, Jackson Immunoresearch, West Grove, $\mathrm{PA}, \mathrm{USA})$ for $2 \mathrm{~h}$ at room temperature, followed by visualization using a fluorescence microscope (Leica Microsystems).

\section{FJC staining}

Degenerating neurons were evaluated by FJC staining as previously reported [37]. According to manufacturer's 
instructions, slides were immersed in $1 \%$ sodium hydroxide solution for $5 \mathrm{~min}$, followed by rinsing in 70\% ethanol for $2 \mathrm{~min}$, and were subsequently transferred into distilled water for $2 \mathrm{~min}$. After being incubated in $0.06 \%$ potassium permanganate solution for $10 \mathrm{~min}$, the sliders were rinsed in distilled water for $2 \mathrm{~min}$ and transferred into a $0.0001 \%$ solution of FJC (Millipore, Billerica, MA, USA) dissolved in $0.1 \%$ acetic acid for $10 \mathrm{~min}$. Slides were rinsed with distilled water three times for 1 min each, dried in a slide incubator for $5 \mathrm{~min}$ at $50^{\circ} \mathrm{C}$, immersed in xylene for $1 \mathrm{~min}$, and finally cover slipped with DPX (Sigma-Aldrich). The sections were visualized in blinded manner with a fluorescence microscope, Leica DMi8 (Leica Micro-systems). FJC-positive neurons were manually counted in the peri-hematoma regions of six sections per brain at $\times 200$ magnification using ImageJ software (Image J 1.4, NIH). The data were averaged and expressed as positive cells $/ \mathrm{mm}^{2}$.

\section{TUNEL staining}

For quantification of neuronal apoptosis, double staining of NeuN (green) and TUNEL (red) was performed using in situ Apoptosis Detection Kit (Roche, Indianapolis, IN, USA) according to the manufacturer's instructions at 24 $\mathrm{h}$ after ICH [38]. The number of TUNEL-positive neurons was counted manually in the peri-hematoma area of six sections per brain at $\times 200$ magnification using Image J software (Image J 1.4, NIH). Data was expressed as the ratio of TUNEL-positive neurons (\%).

\section{Statistical analysis}

All data were expressed as the mean and standard deviation (mean \pm SD). Statistical analysis was performed with Graph Pad Prism (Graph Pad Software, San Diego, CA, USA). Statistical evaluation of the data was performed by analysis of variance (ANOVA), followed by Tukey multiple-comparison post hoc analysis. Sample sizes were calculated assuming a type I error rate $=0.05$ and power $=0.8$ on a two-sided test in this study. Statistical significance was defined as $p<0.05$.

\section{Results}

\section{Animal mortality and exclusion}

Of a total of 216 mice used, 166 mice were subjected to $\mathrm{ICH}$. No mice died in sham or naïve groups. The overall mortality of mice was $10.84 \%$ (18/166). Four mice were excluded from this study due to lack of hemorrhage. The summary of experimental groups, animal numbers, and mortality rate are listed in a table (Additional file 1: Table S1).

Time course and spatial expressions of TREM2 after ICH The endogenous expression of TREM2 was assessed by western blot analysis at 0 (sham), 3, 6, 12, 24, and $72 \mathrm{~h}$ in the ipsilateral/right cerebral hemispheres after $\mathrm{ICH}$. The results showed that the expression of TREM2 was significantly increased at $12 \mathrm{~h}$, reached to the highest level at $24 \mathrm{~h}$, and decreased at $72 \mathrm{~h}$ after ICH when compared with sham group ( $p<0.05$, Fig. 2a). Double immunofluorescence staining was performed to determine the cellular localization of TREM2 at $24 \mathrm{~h}$ after ICH. The results showed that TREM2 was expressed in microglia (Iba-1), astrocytes (GFAP), and neurons $(\mathrm{NeuN})$ in the perihematomal area at $24 \mathrm{~h}$ after $\mathrm{ICH}$ (Fig. 2b).

COG1410 treatment reduced brain edema and attenuated neurological deficits at 24 and $72 \mathrm{~h}$ after $\mathrm{ICH}$

Three different dosages of COG1410 were used to choose the optimal dosage in attenuating $\mathrm{ICH}$-induced brain injury. The brain water content in the ipsilateral basal ganglia and ipsilateral cortex was significantly increased in the ICH groups when compared with sham group at $24 \mathrm{~h}$ after ICH $(p<0.05$, Fig. 3a, e), which was significantly reduced after COG1410 administration $(200 \mu \mathrm{g} / \mathrm{kg})(p<0.05$, Fig. 2a, e). Significant neurological deficits were observed in ICH groups at $24 \mathrm{~h}$ when compared with sham group at $24 \mathrm{~h}$ as assessed by the modified Garcia test $(p<0.05$, Fig. $3 \mathrm{~b})$, corner turn test $(p<0.05$, Fig. $3 \mathrm{c})$, and forelimb placement test $(p<0.05$, Fig. 3d). Administration of COG1410 $(200 \mu \mathrm{g} / \mathrm{kg})$ significantly improved neurological outcomes $(p<0.05$, Fig. $3 \mathrm{~b}-\mathrm{d})$ at $24 \mathrm{~h}$ after ICH when compared with $\mathrm{ICH}+$ vehicle group. To further verify the treatment efficacy of COG1410 $(200 \mu \mathrm{g} / \mathrm{kg})$, brain water content and neurobehavioral tests were also performed at $72 \mathrm{~h}$ after $\mathrm{ICH}$. Consistently, ICH + COG1410 (200 $\mu \mathrm{g} / \mathrm{kg})$ group significantly reduced brain water content in the ipsilateral basal ganglia and ipsilateral cortex $(p<0.05$, Fig. 3e) and improved neurological functions $(p<0.05$, Fig. $3 \mathrm{f}-\mathrm{h})$ when compared with $\mathrm{ICH}+$ vehicle group at $72 \mathrm{~h}$ after $\mathrm{ICH}$. Therefore, a middle dosage of COG1410 was selected for long-term and mechanistic studies.

\section{COG1410 treatment inhibited microglia/macrophage activation, neutrophil infiltration, and the expression of TNF- $\alpha$ and IL-1 $\beta$ at $24 \mathrm{~h}$ after ICH}

The levels of Iba- 1 and MPO in the perihematomal area at $24 \mathrm{~h}$ after ICH were performed to detect microglia/ macrophage activation and neutrophil infiltration by immunofluorescence staining. The results showed that the numbers of Iba- 1 and MPO-positive cells in the perihematomal area were significantly increased in $\mathrm{ICH}+$ vehicle group when compared with sham group at $24 \mathrm{~h}$ after ICH $(p<0.05$, Fig. 4a-f). However, COG1410 treatment significantly decreased the numbers of Iba- 1 and MPO-positive cells in the perihematomal area when compared with $\mathrm{ICH}+$ vehicle group at $24 \mathrm{~h}$ after $\mathrm{ICH}$ 

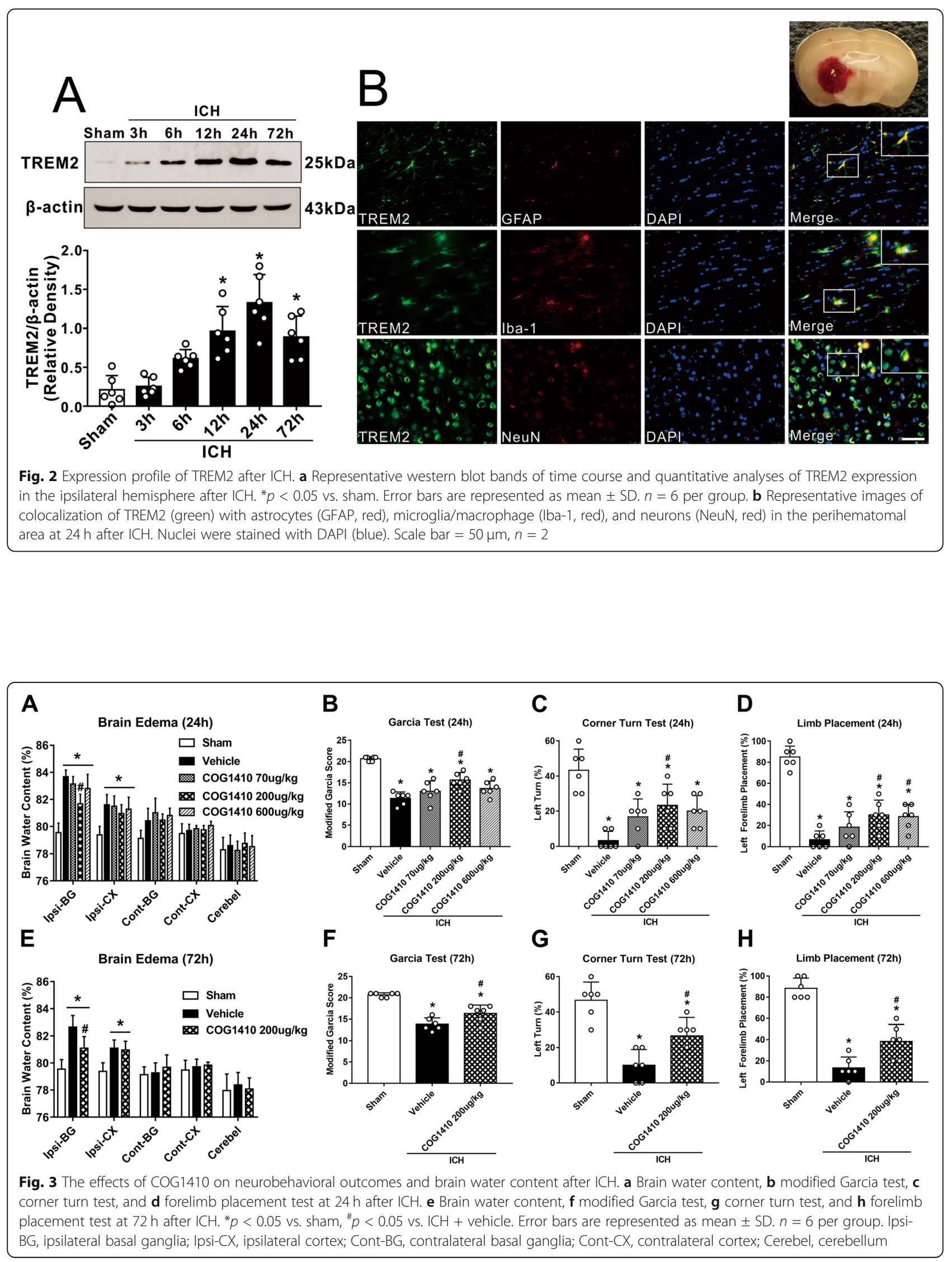


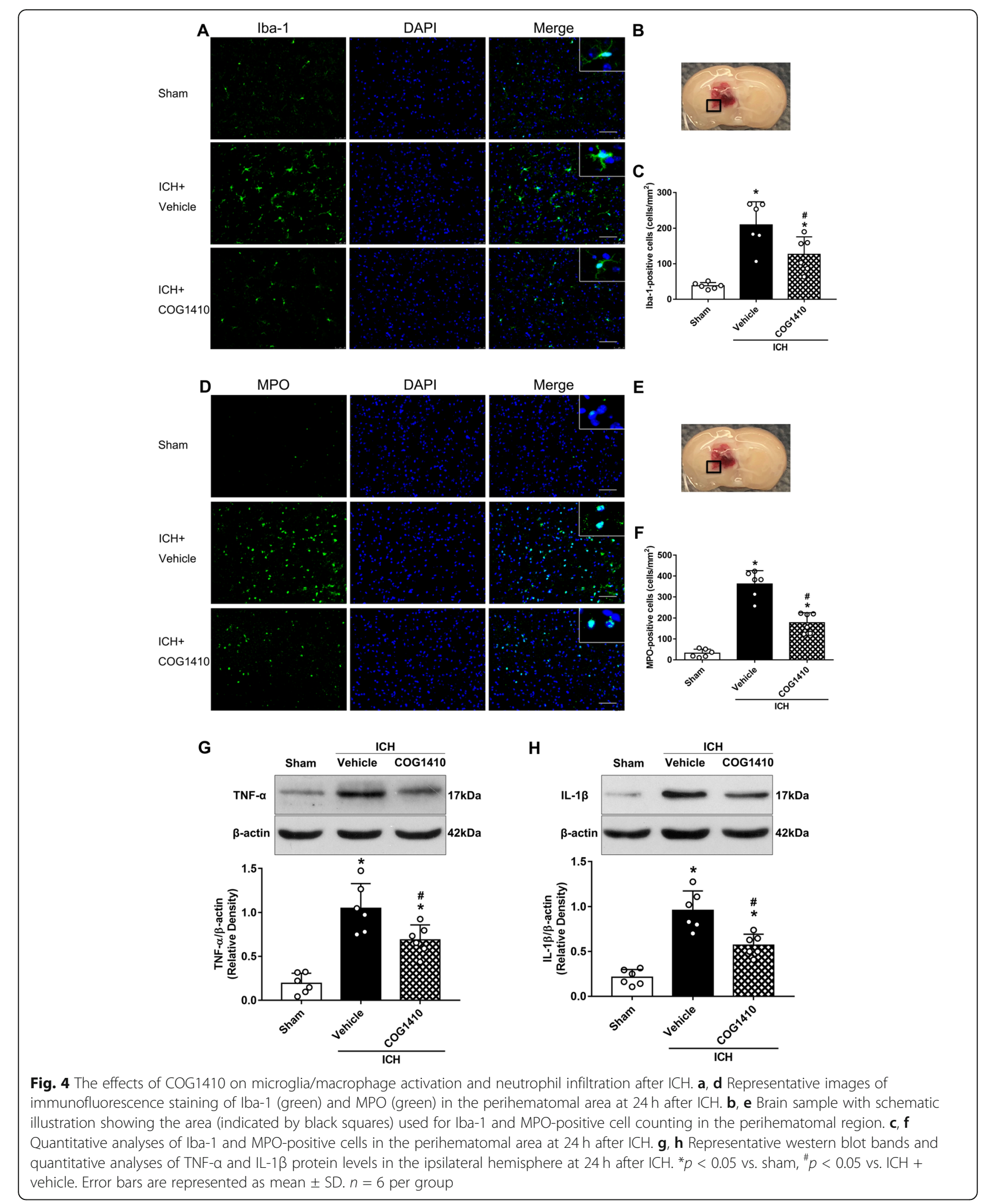


$(p<0.05$, Fig. 4a-f). Additionally, the expression of proinflammatory mediators TNF- $\alpha$ and IL- $1 \beta$ at $24 \mathrm{~h}$ after $\mathrm{ICH}$ were measured by western blot. The results showed that the expression of TNF- $\alpha$ and IL- $1 \beta$ in the ipsilateral hemisphere were significantly decreased with COG1410 treatment when compared with $\mathrm{ICH}+$ vehicle group at $24 \mathrm{~h}$ after $\mathrm{ICH}(p<0.05$, Fig. $4 \mathrm{~g}, \mathrm{~h})$.

COG1410 treatment attenuated neuronal apoptotic death and the expression of $\mathrm{Bcl}-2$ and $\mathrm{Bax}$ at $24 \mathrm{~h}$ after ICH

Degenerating and apoptotic neurons in the perihematomal area at $24 \mathrm{~h}$ after $\mathrm{ICH}$ were assessed by FJC and TUNEL staining. The results revealed that FJC-positive neurons and TUNEL-positive neurons of the perihematomal area in $\mathrm{ICH}+$ vehicle group significantly increased when compared with sham group at $24 \mathrm{~h}$ after $\mathrm{ICH}$, but that COG1410 treatment reduced the numbers of FJCpositive neurons and TUNEL-positive neurons $(p<0.05$, Fig. 5a-f). Meanwhile, the expression of apoptotic molecular markers Bcl-2 and Bax at $24 \mathrm{~h}$ after ICH were measured by western blot. The results showed that the expression of Bcl-2 was significantly increased and the expression of Bax was significantly decreased with COG1410 treatment when compared with $\mathrm{ICH}+$ vehicle group in the ipsilateral hemisphere at $24 \mathrm{~h}$ after $\mathrm{ICH}(p$ $<0.05$, Fig. 5g, h).

\section{COG1410 treatment improved long-term neurological functions after $\mathrm{ICH}$}

In the probe quadrant trial, the mice in $\mathrm{ICH}+$ vehicle group spent remarkably less time in the target quadrant when compared with sham group, while the reference memory deficits were significantly increased with COG1410 treatment $(p<0.05$, Fig. 6a, d). In the Morris water maze test, escape latency and swim distance to find the platform were significantly increased in $\mathrm{ICH}+$ vehicle group when compared with sham group ( $p<$ 0.05 , Fig. 6b, c). However, a significant decrease in escape latency on blocks 3 to 5 and a significantly shorter swim distance on blocks 4 and 5 were observed in $\mathrm{ICH}$ + COG1410 group ( $p<0.05$, Fig. 6b, c).

In the Rotarod test and foot fault tests, the mice in $\mathrm{ICH}+$ vehicle group had significantly shorter falling latency and more foot faults of the left forelimb when compared with sham groups in the first, second, and third week after ICH ( $p<0.05$, Fig. 6e, f). However, COG1410 treatment significantly improved the neurological deficits when compared with the $\mathrm{ICH}+$ vehicle group ( $p<0.05$, Fig. $6 \mathrm{e}, \mathrm{f})$.

\section{TREM2 siRNA aggravated neurological deficits and} decreased the expression of TREM2 in naïve and ICH mice The knockdown efficacy of TREM2 siRNA was verified by western blotting and neurobehavior tests in naïve and
ICH mice. TREM2 siRNA administered by intracerebroventricular injection significantly decreased the expression of TREM2 in the ipsilateral hemisphere and aggravated neurological deficits in naive + TREM2 siRNA group when compared with naïve+ scr siRNA group ( $p<0.05$, Fig. $7 \mathrm{a}-\mathrm{d}$ ). Similarly, the expression of TREM2 was significantly decreased and neurological deficits was aggravated in ICH + TREM2 siRNA group when compared with $\mathrm{ICH}+$ scr siRNA group $(p<0.05$, Fig. $7 \mathrm{a}-\mathrm{d})$.

\section{TREM2 siRNA and LY294002 abolished the} neuroprotective effects of COG1410 on neurological functions at $24 \mathrm{~h}$ after ICH

Administration of TREM2 siRNA significantly aggravated the neurological deficits assessed by the modified Garcia $(p<0.05$, Fig. 8a), corner turn $(p<0.05$, Fig. $8 \mathrm{~b})$, and forelimb placement tests $(p<0.05$, Fig. $8 \mathrm{c})$ in $\mathrm{ICH}+$ COG1410 + TREM2 siRNA group when compared with $\mathrm{ICH}+$ COG1410 + scr siRNA group at $24 \mathrm{~h}$ after ICH. Similarly, LY294002 treatment exacerbated the neurological deficits in ICH + COG1410 + LY294002 group when compared with ICH + COG1410 + DMSO group at $24 \mathrm{~h}$ after $\mathrm{ICH}(p<0.05$, Fig. $8 \mathrm{a}-\mathrm{c})$.

\section{COG1410 suppressed neuroinflammation and neuronal apoptosis via activation of the TREM2/PI3K/Akt signaling pathway at $\mathbf{2 4} \mathrm{h}$ after $\mathrm{ICH}$}

After COG1410 treatment, the expression of TREM2 significantly increased when compared with both sham and $\mathrm{ICH}+$ vehicle groups $(p<0.05$, Fig. $8 \mathrm{~d}$, e). Moreover, the expression of PI3K, p-Akt, and Bcl-2 was significantly decreased, while the expression of TNF- $\alpha$, IL$1 \beta$, and Bax was remarkably increased in $\mathrm{ICH}+$ vehicle group when compared with sham group at $24 \mathrm{~h}$ after ICH $(p<0.05$, Fig. 8d, f-k). COG1410 treatment significantly increased the expression of PI3K, p-Akt, and Bcl2 and significantly decreased the expression of TNF- $\alpha$, IL-1 $\beta$, and Bax in ICH + COG1410 group when compared with $\mathrm{ICH}+$ vehicle group at $24 \mathrm{~h}$ after $\mathrm{ICH}(p<$ 0.05, Fig. 8d, f-k). However, knockdown of TREM2 with TREM2 siRNA remarkably decreased the expression of TREM2, PI3K, p-Akt, and Bcl-2 and increased the expression of TNF- $\alpha$, IL-1 $\beta$, and Bax in ICH + COG1410 + TREM2 siRNA group when compared with $\mathrm{ICH}+$ COG1410 + scr siRNA group at 24h after ICH $(p<$ 0.05 , Fig. $8 \mathrm{~d}-\mathrm{k})$. Consistently, pretreatment with LY294002 significantly decreased the expression of PI3K, p-Akt, and Bcl-2, while increased the expression of TNF- $\alpha$, IL-1 $\beta$, and Bax in ICH + COG1410 + LY294002 group when compared with $\mathrm{ICH}+\mathrm{COG} 1410+\mathrm{DMSO}$ group at $24 \mathrm{~h}$ after $\mathrm{ICH}(p<0.05$, Fig. $8 \mathrm{~d}, \mathrm{f}-\mathrm{k})$. 


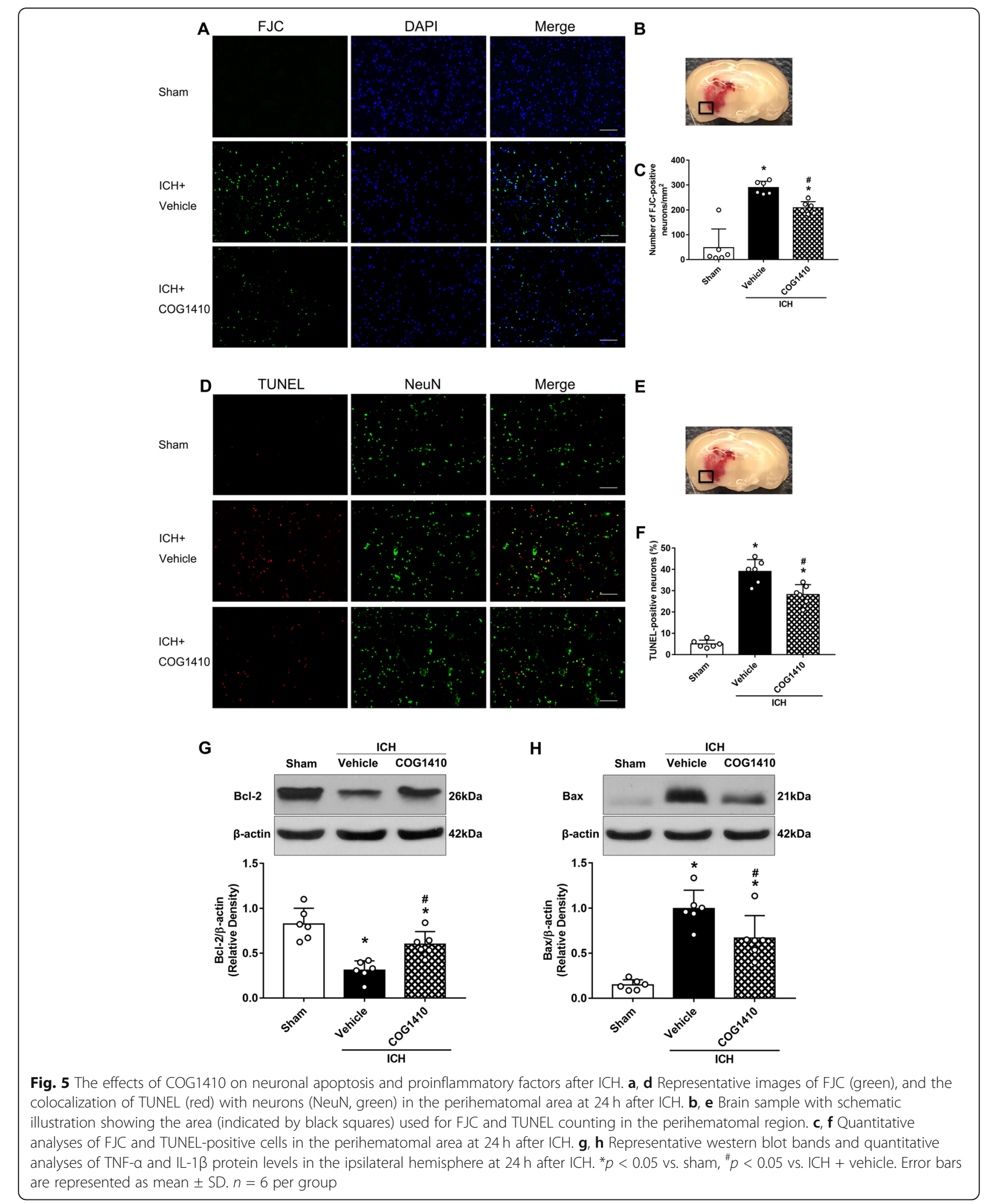




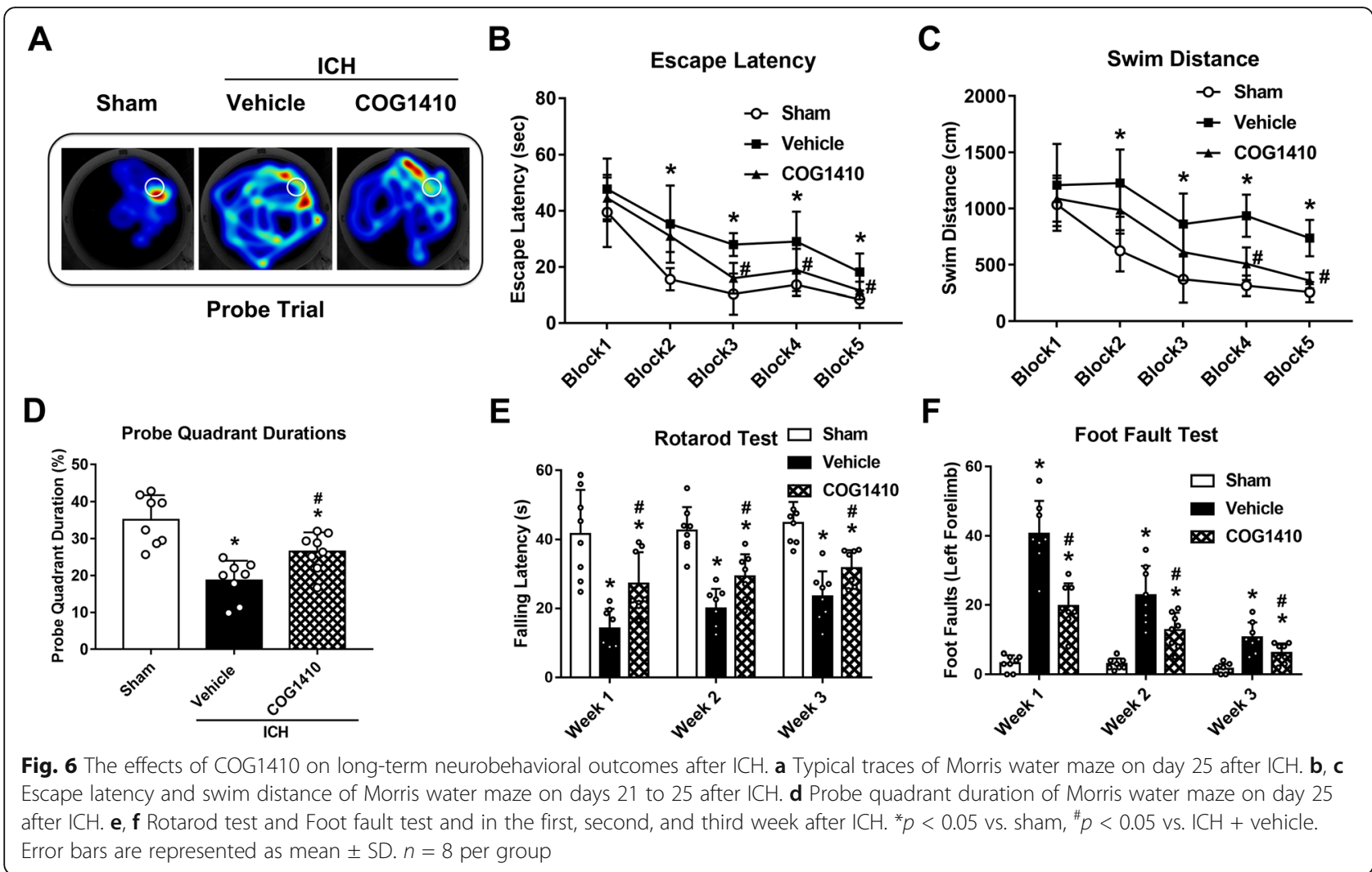

\section{Discussion}

In the current study, we first investigated the neuroprotective effects of TREM2 activation and explored its underlying mechanism in a mouse model of $\mathrm{ICH}$. We demonstrated that activation of TREM2 with COG1410 improved both short- and long-term neurological functions, reduced brain edema, inhibited microglia/macrophage activation and neutrophil infiltration, and suppressed neuronal apoptotic cell death in perihematomal areas after ICH. In addition, knockdown of endogenous TREM2 by
TREM2 siRNA aggravated neurological deficits and decreased the expression of TREM2 in naive and ICH mice. Moreover, intranasal administration of COG1410 was associated with upregulation of TREM2, PI3K, p-Akt, and Bcl-2 and with downregulation of TNF- $\alpha$, IL-1 $\beta$, and Bax after ICH. However, blockage of TREM2 or silencing of PI3K reversed the beneficial effects of COG1410 on neurological functions and the expression of proinflammatory mediators and apoptotic markers. Finally, our findings suggested that TREM2 activation may attenuate neuroinflammation and

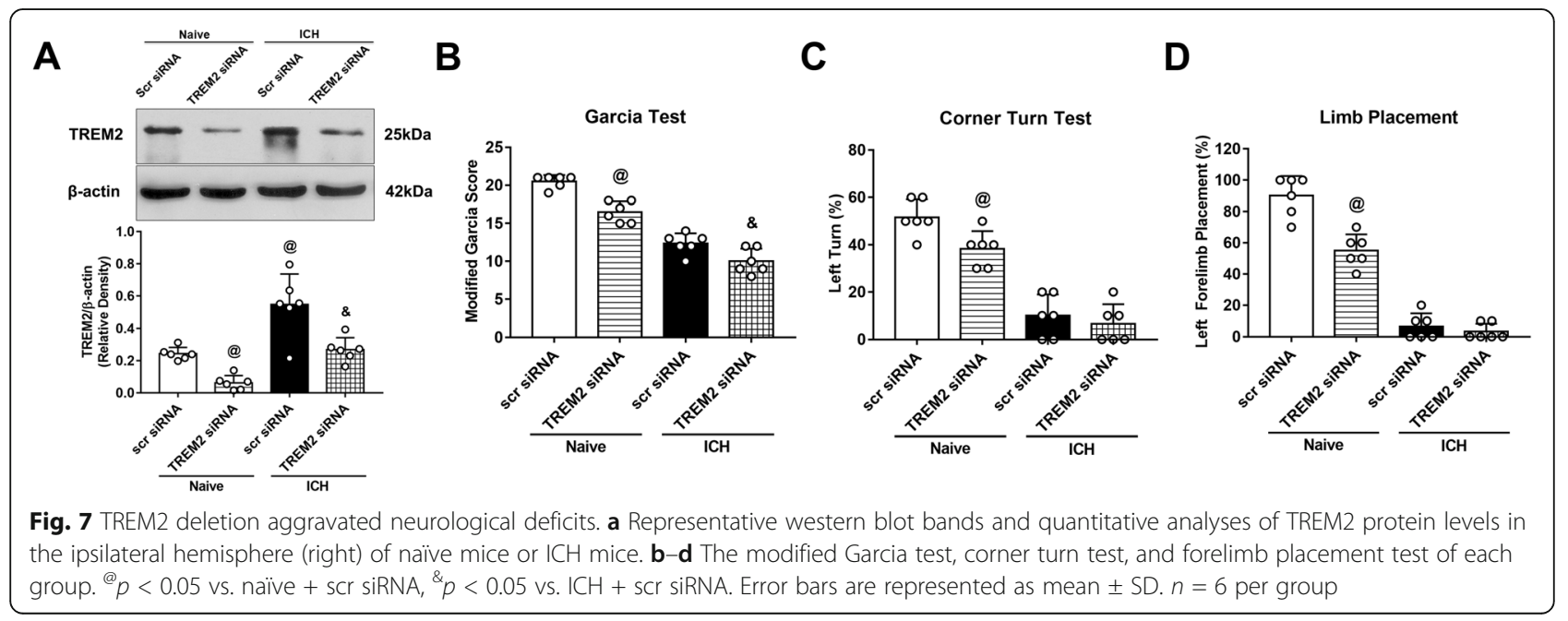




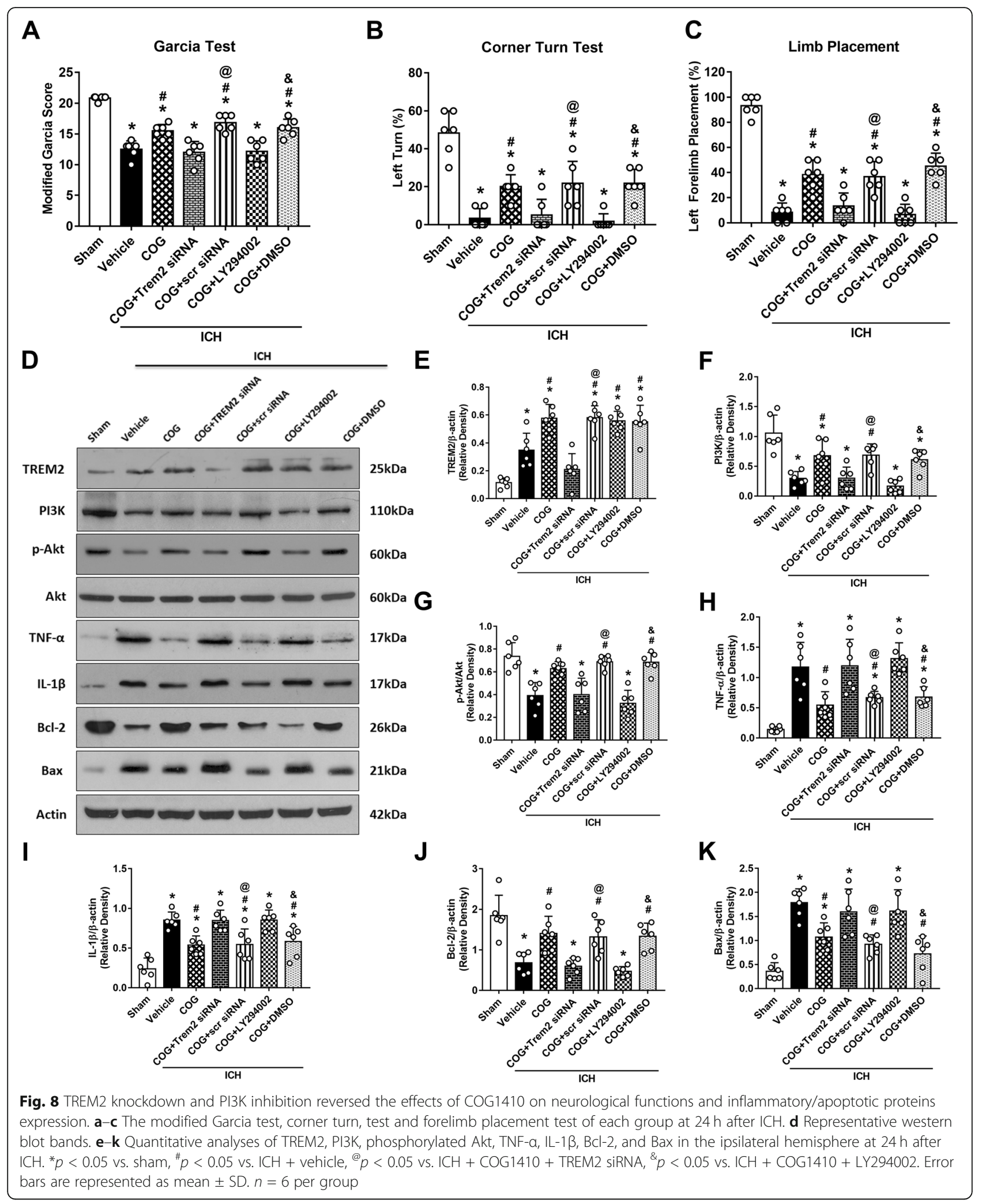


neuronal apoptosis after $\mathrm{ICH}$, which was, at least in part, mediated by activation of PI3K/Akt signaling pathway.

There are two major and best-characterized members in the TREM family, TREM1 and TREM2, which are immunomodulatory receptors that have important roles in innate and adaptive immunity. TREM1 is thought to be an amplifier of the immune response, while TREM2 is believed to be a negative regulator [39]. TREM2 protein is mainly expressed on myeloid lineage cells and, in particular, on microglial cells, which have approximately 300 -fold higher densities of the protein than neurons and other glial cells in the central nervous system (CNS) $[40,41]$. Interestingly, our immunofluorescence staining results showed that TREM2 was expressed not only on microglia but also on astrocytes and neurons following $\mathrm{ICH}$. We also observed that the endogenous expression of TREM2 in the ipsilateral/right hemisphere of brain was increased in a time-dependent manner and reached a peak at $24 \mathrm{~h}$ after ICH. A previous study reported that the expression of TREM2 was upregulated as early as 6 $\mathrm{h}$ and peaked at approximately $72 \mathrm{~h}$ in a rat model of cerebral ischemia [23]. Another study demonstrated that mRNA and protein expression of TREM2 were both markedly increased in the rat brain after ischemia/reperfusion injury [25]. Our data were consistent with previous studies, but the mechanisms of the TREM2 change after ICH remain incompletely understood. It is well known that microglia activation occurs as early as $1 \mathrm{~h}$ in a collagenase-induced ICH model and that the number of activated microglia/macrophages peaks at $72 \mathrm{~h}$ and returns to normal level several weeks after the insult [42]. Moreover, TREM2 is primarily expressed on microglia in the brain. Given the above, TREM2 may be upregulated to regulate the inflammatory response during the acute phase of $\mathrm{ICH}$.

Numerous studies have revealed that TREM2 exerts anti-inflammatory properties and promotes phagocytosis of apoptotic neuronal cells in neurodegenerative diseases, liver ischemia/reperfusion injury, and bacterial infections [20, 21, 32, 43, 44]. A previous study reported that TREM2 deficiency exacerbated uncontrolled inflammation in a model of autoimmune encephalomyelitis [45]. Increasing evidence has shown that upregulation of TREM2 results in strong neuroprotective effects by alleviating neuroinflammation in experimental cerebral ischemia [24, 25, 33]. Specifically, an in vivo and in vitro study demonstrated that TREM2 activation promoted microglial switching from the detrimental M1 phenotype to the beneficial M2 phenotype and that as a result decreased the number of apoptotic neurons after ischemic damage [23]. However, the potential therapeutic effects targeting TREM2 in hemorrhagic stroke have yet to be elucidated.

Recent studies identified that apoE is a novel and high-affinity ligand for TREM2 and that the TREM2- binding domain is found in amino acids 130-149 of apoE [15-19]. ApoE is the major apolipoprotein synthesized in the CNS, which not only serves as an important mediator of cholesterol and lipid transport, but also affords neuroprotective effects via multiple mechanisms including anti-inflammatory, anti-excitotoxic, and anti-oxidant properties after brain injury [46-48]. ApoE exists three isoforms, designated apoE2, apoE3, and apoE4. However, apoE4 is associated with higher risk of cardiovascular morbidity, cognitive impairments during aging, and Alzheimer's disease $[49,50]$. However, like most other proteins, the intact apoE holoprotein is too large to cross the BBB because of its 34-kDa molecular weight. Thus, from a translational perspective, the development of apoE-mimetic peptides with smaller molecular weights as alternative therapeutic choices for CNS disease treatment is greatly desirable.

COG1410 is a peptide derived from apoE amino acid residues 138-149 of the receptor region of the apoE holoprotein with aminoisobutyric acid (Aib) substitutions at positions 140 and 145 (acetyl-AS-Aib-LRKLAib-KRLL-amide). Emerging studies have indicated that brain edema is significantly associated with hematoma enlargement and increased midline shift, which lead to poor neurological outcome after ICH [51]. In our study, we found that COG1410 treatment reduced brain edema and attenuated neurological deficits at 24 and $72 \mathrm{~h}$ after ICH. Furthermore, COG1410 treatment improved long-term movement coordination ability, spatial learning, and memory. In addition, ICH-induced microglia/macrophage activation and neutrophil infiltration can further promote the release of proinflammatory mediators and neuronal apoptotic molecular markers, which ultimately result in neuroinflammation and neuronal apoptosis [5]. On the contrary, several studies have demonstrated that COG1410 treatment improves functional recovery and alleviates neuroinflammation and neuronal apoptosis in experimental ischemic stroke, hemorrhage stroke, and traumatic brain injury [52-55].

Consistent with previous studies, our data showed that COG1410 treatment inhibited microglia/macrophage activation, neutrophil infiltration, and neuronal apoptotic death as measured by immunofluorescence, and FJC and TUNEL staining, and downregulated the expression of TNF- $\alpha$, IL- $1 \beta$, Bcl- 2 and Bax, as measured by western blotting, at $24 \mathrm{~h}$ after $\mathrm{ICH}$. Furthermore, our data showed that TREM2 knockdown by siRNA and PI3K inhibition by the specific inhibitor LY294002 significantly reversed the anti-inflammatory and anti-apoptotic effects of apoE-mimic peptide COG1410. These data suggested the apoE-mimic peptide inhibited neuroinflammation and neuronal apoptosis by activating the PI3K/Akt pathway through TREM2 after ICH. 
Several limitations need to be mentioned in this study. First, TREM2 plays multifunctional roles in innate and adaptive immunity. Further research is needed to investigate the other mechanisms underlying the neuroprotective effects of TREM2 against secondary brain injury after ICH. Second, since our double immunofluorescence staining showed that TREM2 is not only expressed on microglia and neurons after $\mathrm{ICH}$, detailed roles of TREM2 on other CNS cells, such as astrocytes, are necessary for further study. Third, apoE has been shown to be bound and internalized via receptor-mediated endocytosis by other receptors, including the low-density lipoprotein receptor, very-low density lipoprotein receptor, and apoE receptor 2 in the CNS. How the apoEmimic peptide affects these receptors and the related pathways and the specific mechanism associated with peptide activation of TREM2 should be more deeply evaluated. Besides, the silencing efficiency of TREM2 siRNA upon local injection in mouse brain is also a concern in our research process. Recent studies and our present study have demonstrated effectiveness of local knockdown of genes using siRNAs in the brain [56, 57]. However, the time window and tissue area of siRNA are very limited, because of the poor intracellular uptake and low blood stability of siRNA. This study only focused on the early pathophysiological changes (within $72 \mathrm{~h}$ ) around the hematoma after $\mathrm{ICH}$, the effects of TREM2 on specific regions/cell types, and the long-term prognosis after ICH require more precise gene-editing techniques, such as the use of cre/loxp mice to edit TREM2 genes in specific cells. Last but not least, since bacterial collagenase was used to induce $\mathrm{ICH}$ in this study, we cannot exclude the possibility of initiating greater neuroinflammation than that found in autologous blood-induced ICH model. Thus, further studies are needed to investigate the neuroprotective effects of activation of TREM2 with apoE-mimic peptide after $\mathrm{ICH}$ by using the two models.

\section{Conclusions}

In conclusion, we demonstrated that TREM2 activation with apoE-mimic peptide attenuated neuroinflammation and neuronal apoptosis after $\mathrm{ICH}$, which was, at least in part, mediated by activation of PI3K/Akt signaling pathway. Therefore, TREM2 activation may be a potential therapeutic strategy in the management of $\mathrm{ICH}$ patients.

\section{Supplementary information}

Supplementary information accompanies this paper at https://doi.org/10. 1186/s12974-020-01853-x.

Additional file 1: Table S1. Summary of experimental groups and mortality rate in the study.

\section{Abbreviations}

Akt: Protein kinase B; apoE: Apolipoprotein E; BBB: Blood-brain barrier CNS: Central nervous system; DMSO: Dimethylsulfoxide; FJC: Fluoro-Jade C; ICH: Intracerebral hemorrhage; IL: Interleukin; PBS: Phosphate-buffered saline; PI3K: Phosphatidylinositol 3-kinase; siRNA: Small interfering RNA; TNF: Tumor necrosis factor; TREM2: Triggering receptor expressed on myeloid cells 2;

TUNEL: Terminal deoxynucleotidyl transferase dUTP nick end labeling

\section{Acknowledgements}

We thank prof. Michael P. Vitek for providing COG1410.

\section{Authors' contributions}

SPC and PS worked on experimental design. SPC, JHP, YJM, SSX, FY, and HZ conducted the experiments, analyzed the data, and drafted the manuscript. PS and YJ worked on the manuscript revision. NW, JHZ, and HQZ participated in the experimental design, data analysis and interpretation, and manuscript preparation. The authors read and approved the final manuscript.

\section{Funding}

This study is supported by National Institutes of Health (NS091042, NS082184) China Postdoctoral Science Foundation (2019 M660713), and National Natural Science Foundation of China $(81801176,81971132,8167120)$.

Availability of data and materials

The datasets analyzed during the current study are available from the corresponding author on reasonable request.

\section{Ethics approval and consent to participate}

All animal experiments were approved by the Institutional Animal Care and Use Committee at Loma Linda University. The study followed the Health's

Guide for the Care and Use of Laboratory Animals (National Research

Council) and complied with the ARRIVE guidelines for reporting in vivo experiments.

Consent for publication

Not applicable.

\section{Competing interests}

The authors declare that they have no competing interests.

\section{Author details}

${ }^{1}$ Department of Neurosurgery, Xuanwu Hospital, Capital Medical University, China International Neuroscience Institute (China-INI), No. 45 Changchun Street, Xicheng District, Beijing 10053, China. ${ }^{2}$ Department of Physiology and Pharmacology, Department of Neurosurgery and Anesthesiology, School of Medicine, Loma Linda University, Risley Hall, Room 219, 11041 Campus Street, Loma Linda, CA 92354, USA. ${ }^{3}$ Department of Neurosurgery, The Affiliated Hospital of Southwest Medical University, Luzhou 646000, China. ${ }^{4}$ Laboratory of Neurological Diseases and Brain Functions, The Affiliated Hospital of Southwest Medical University, Luzhou 646000, Sichuan, China. ${ }^{5}$ Department of Neurosurgery, Loma Linda University Medical Center, Loma Linda, CA 92354, USA.

Received: 18 September 2019 Accepted: 21 May 2020

Published online: 28 May 2020

\section{References}

1. Li X, Feng D, Chen G. An update on medical treatment for intracerebral hemorrhage. Transl Stroke Res. 2018;9:549-54.

2. Zhao L, Chen S, Sherchan P, Ding Y, Zhao W, Guo Z, Yu J, Tang J, Zhang JH. Recombinant CTRP9 administration attenuates neuroinflammation via activating adiponectin receptor 1 after intracerebral hemorrhage in mice. J Neuroinflammation. 2018;15:215.

3. Chen S, Yang Q, Chen G, Zhang JH. An update on inflammation in the acute phase of intracerebral hemorrhage. Transl Stroke Res. 2015;6:4-8.

4. Mendelow AD, Gregson BA, Rowan EN, Murray GD, Gholkar A, Mitchell PM, Investigators SI. Early surgery versus initial conservative treatment in patients with spontaneous supratentorial lobar intracerebral haematomas (STICH II): a randomised trial. Lancet. 2013;382:397-408. 
5. Zhou Y, Wang Y, Wang J, Anne Stetler R, Yang QW. Inflammation in intracerebral hemorrhage: from mechanisms to clinical translation. Prog Neurobiol. 2014;115:25-44.

6. Chen S, Zhao L, Sherchan P, Ding Y, Yu J, Nowrangi D, Tang J, Xia Y, Zhang $\mathrm{JH}$. Activation of melanocortin receptor 4 with RO27-3225 attenuates neuroinflammation through AMPK/JNK/p38 MAPK pathway after intracerebral hemorrhage in mice. J Neuroinflammation. 2018;15:106.

7. Wang T, Nowrangi D, Yu L, Lu T, Tang J, Han B, Ding Y, Fu F, Zhang JH. Activation of dopamine D1 receptor decreased NLRP3-mediated inflammation in intracerebral hemorrhage mice. J Neuroinflammation. 2018;15:2.

8. Ziai WC. Hematology and inflammatory signaling of intracerebral hemorrhage. Stroke. 2013;44:S74-8.

9. Wu CH, Shyue SK, Hung TH, Wen S, Lin CC, Chang CF, Chen SF. Genetic deletion or pharmacological inhibition of soluble epoxide hydrolase reduces brain damage and attenuates neuroinflammation after intracerebral hemorrhage. J Neuroinflammation. 2017;14:230.

10. Kono H, Rock KL. How dying cells alert the immune system to danger. Nat Rev Immunol. 2008;8:279-89.

11. Ulrich JD, Holtzman DM. TREM2 function in Alzheimer's disease and neurodegeneration. ACS Chem Neurosci. 2016;7:420-7.

12. Kober DL, Brett TJ. TREM2-ligand interactions in health and disease. J Mol Biol. 2017;429:1607-29.

13. Bouchon A, Dietrich J, Colonna M. Cutting edge: inflammatory responses can be triggered by TREM-1, a novel receptor expressed on neutrophils and monocytes. J Immunol. 2000;164:4991-5.

14. Takahashi K, Rochford CD, Neumann H. Clearance of apoptotic neurons without inflammation by microglial triggering receptor expressed on myeloid cells-2. J Exp Med. 2005;201:647-57.

15. Atagi Y, Liu CC, Painter MM, Chen XF, Verbeeck C, Zheng H, Li X, Rademakers R, Kang SS, Xu H, et al. Apolipoprotein E is a ligand for triggering receptor expressed on myeloid cells 2 (TREM2). J Biol Chem. 2015;290:26043-50.

16. Bailey CC, DeVaux LB, Farzan M. The triggering receptor expressed on myeloid cells 2 binds apolipoprotein E. J Biol Chem. 2015;290:26033-42.

17. Yeh FL, Wang Y, Tom I, Gonzalez LC, Sheng M. TREM2 binds to apolipoproteins, including APOE and CLU/APOJ, and thereby facilitates uptake of amyloid-beta by microglia. Neuron. 2016;91:328-40.

18. Jendresen C, Arskog V, Daws MR, Nilsson LN. The Alzheimer's disease risk factors apolipoprotein E and TREM2 are linked in a receptor signaling pathway. J Neuroinflammation. 2017:14:59.

19. Krasemann S, Madore C, Cialic R, Baufeld C, Calcagno N, El Fatimy R, Beckers $L, O$ 'Loughlin E, Xu Y, Fanek Z, et al. The TREM2-APOE pathway drives the transcriptional phenotype of dysfunctional microglia in neurodegenerative diseases. Immunity. 2017:47:566-81 e569.

20. Raha AA, Henderson JW, Stott SR, Vuono R, Foscarin S, Friedland RP, Zaman $\mathrm{SH}$, Raha-Chowdhury R. Neuroprotective effect of TREM-2 in aging and Alzheimer's disease model. J Alzheimers Dis. 2017:55:199-217.

21. Takahashi K, Prinz M, Stagi M, Chechneva O, Neumann H. TREM2-transduced myeloid precursors mediate nervous tissue debris clearance and facilitate recovery in an animal model of multiple sclerosis. PLoS Med. 2007:4:e124.

22. Jay TR, von Saucken VE, Landreth GE. TREM2 in neurodegenerative diseases. Mol Neurodegener. 2017;12:56.

23. Zhai Q, Li F, Chen X, Jia J, Sun S, Zhou D, Ma L, Jiang T, Bai F, Xiong L, Wang $Q$. Triggering receptor expressed on myeloid cells 2, a novel regulator of immunocyte phenotypes, confers neuroprotection by relieving neuroinflammation. Anesthesiology. 2017;127:98-110.

24. Kawabori M, Kacimi R, Kauppinen T, Calosing C, Kim JY, Hsieh CL, Nakamura MC, Yenari MA. Triggering receptor expressed on myeloid cells 2 (TREM2) deficiency attenuates phagocytic activities of microglia and exacerbates ischemic damage in experimental stroke. J Neurosci. 2015;35:3384-96.

25. Wu R, Li X, Xu P, Huang L, Cheng J, Huang X, Jiang J, Wu LJ, Tang Y. TREM2 protects against cerebral ischemia/reperfusion injury. Mol Brain. 2017;10:20.

26. Kawabori M, Hokari M, Zheng Z, Kim JY, Calosing C, Hsieh CL, Nakamura MC, Yenari MA. Triggering receptor expressed on myeloid cells-2 correlates to hypothermic neuroprotection in ischemic stroke. Ther Hypothermia Temp Manag. 2013;3:189-98.

27. Zhu M, Li D, Wu Y, Huang X, Wu M. TREM-2 promotes macrophagemediated eradication of Pseudomonas aeruginosa via a PI3K/Akt pathway. Scand J Immunol. 2014;79:187-96.

28. Lv MR, Li B, Wang MG, Meng FG, Yu JJ, Guo F, Li Y. Activation of the PI3KAkt pathway promotes neuroprotection of the delta-opioid receptor agonist against cerebral ischemia-reperfusion injury in rat models. Biomed Pharmacother. 2017;93:230-7.

29. Tu XK, Zhang HB, Shi SS, Liang RS, Wang CH, Chen CM, Yang WZ. 5-LOX inhibitor zileuton reduces inflammatory reaction and ischemic brain damage through the activation of PI3K/Akt signaling pathway. Neurochem Res. 2016;41:2779-87.

30. Zhang H, Sheng L, Tao J, Chen R, Li Y, Sun Z, Qian W. Depletion of the triggering receptor expressed on myeloid cells 2 inhibits progression of renal cell carcinoma via regulating related protein expression and PTENPI3K/Akt pathway. Int J Oncol. 2016;49:2498-506.

31. Peng Q, Malhotra S, Torchia JA, Kerr WG, Coggeshall KM, Humphrey MB. TREM2- and DAP12-dependent activation of PI3K requires DAP10 and is inhibited by SHIP1. Sci Signal. 2010;3:ra38.

32. Sun $M$, Zhu M, Chen $K$, Nie X, Deng Q, Hazlett LD, Wu Y, Li M, Wu M, Huang $X$. TREM-2 promotes host resistance against Pseudomonas aeruginosa infection by suppressing corneal inflammation via a PI3K/Akt signaling pathway. Invest Ophthalmol Vis Sci. 2013;54:3451-62.

33. $\mathrm{Xu} \mathrm{H}, \mathrm{Mu} \mathrm{S}$, Qin W. Microglia TREM2 is required for electroacupuncture to attenuate neuroinflammation in focal cerebral ischemia/reperfusion rats. Biochem Biophys Res Commun. 2018;503:3225-34.

34. Tong LS, Shao AW, Ou YB, Guo ZN, Manaenko A, Dixon BJ, Tang J, Lou M, Zhang JH. Recombinant Gas6 augments Axl and facilitates immune restoration in an intracerebral hemorrhage mouse model. J Cereb Blood Flow Metab. 2017;37:1971-81.

35. Yu L, Lu Z, Burchell S, Nowrangi D, Manaenko A, Li X, Xu Y, Xu N, Tang J, Dai $\mathrm{H}$, Zhang $\mathrm{JH}$. Adropin preserves the blood-brain barrier through a Notch1/Hes1 pathway after intracerebral hemorrhage in mice. J Neurochem. 2017;143:750-60.

36. Zhao H, Pan P, Yang Y, Ge H, Chen W, Qu J, Shi J, Cui G, Liu X, Feng H, Chen $Y$. Endogenous hydrogen sulphide attenuates NLRP3 inflammasomemediated neuroinflammation by suppressing the $\mathrm{P} 2 \mathrm{X} 7$ receptor after intracerebral haemorrhage in rats. J Neuroinflammation. 2017;14:163.

37. Mo J, Enkhjargal B, Travis ZD, Zhou K, Wu P, Zhang G, Zhu Q, Zhang T, Peng J, Xu W, et al. AVE 0991 attenuates oxidative stress and neuronal apoptosis via Mas/PKA/CREB/UCP-2 pathway after subarachnoid hemorrhage in rats. Redox Biol. 2018;20:75-86.

38. Xu N, Zhang Y, Doycheva DM, Ding Y, Zhang Y, Tang J, Guo H, Zhang JH. Adiponectin attenuates neuronal apoptosis induced by hypoxia-ischemia via the activation of AdipoR1/APPL1/LKB1/AMPK pathway in neonatal rats. Neuropharmacology. 2018;133:415-28.

39. Sharif $\mathrm{O}, \mathrm{Knapp}$ S. From expression to signaling: roles of TREM-1 and TREM-2 in innate immunity and bacterial infection. Immunobiology. 2008;213:701-13.

40. Li C, Zhao B, Lin C, Gong Z, An X. TREM2 inhibits inflammatory responses in mouse microglia by suppressing the PI3K/NF-kappaB signaling. Cell Biol Int. 2019; 43(4):360-72

41. Ford JW, MCVicar DW. TREM and TREM-like receptors in inflammation and disease. Curr Opin Immunol. 2009;21:38-46.

42. Mracsko E, Veltkamp R. Neuroinflammation after intracerebral hemorrhage. Front Cell Neurosci. 2014;8:388.

43. Nakao T, Ono Y, Dai H, Nakano R, Perez-Gutierrez A, Camirand G, Huang H, Geller DA, Thomson AW. DAP12/TREM2 expression by mouse and human liver DC: functional implications and regulation of liver ischemia-reperfusion injury. Hepatology. 2019;70(2):696-710.

44. Chen Q, Zhang K, Jin Y, Zhu T, Cheng B, Shu Q, Fang X. Triggering receptor expressed on myeloid cells-2 protects against polymicrobial sepsis by enhancing bacterial clearance. Am J Respir Crit Care Med. 2013;188:201-12.

45. Piccio L, Buonsanti C, Mariani M, Cella M, Gilfillan S, Cross AH, Colonna M, Panina-Bordignon P. Blockade of TREM-2 exacerbates experimental autoimmune encephalomyelitis. Eur J Immunol. 2007;37:1290-301.

46. Laskowitz DT, Song P, Wang H, Mace B, Sullivan PM, Vitek MP, Dawson HN. Traumatic brain injury exacerbates neurodegenerative pathology: improvement with an apolipoprotein E-based therapeutic. J Neurotrauma. 2010;27:1983-95.

47. Mace BE, Wang H, Lynch JR, Moss J, Sullivan P, Colton H, Morgan K, Renauld JC, Laskowitz DT. Apolipoprotein E modifies the CNS response to injury via a histamine-mediated pathway. Neurol Res. 2007;29:243-50.

48. Qin X, You H, Cao F, Wu Y, Peng J, Pang J, Xu H, Chen Y, Chen L, Vitek MP, et al. Apolipoprotein $E$ mimetic peptide increases cerebral glucose uptake by reducing blood-brain barrier disruption after controlled cortical impact in mice: an 18F-fluorodeoxyglucose PET/CT study. J Neurotrauma. 2017;34:943-51. 
49. Peng KY, Perez-Gonzalez R, Alldred MJ, Goulbourne CN, Morales-Corraliza J, Saito M, Saito M, Ginsberg SD, Mathews PM, Levy E. Apolipoprotein E4 genotype compromises brain exosome production. Brain. 2018.

50. Peng J, Qin X, Pang J, Wu Y, Dong J, Huang C, Wan W, Yang X, Sun X, Chen L, Jiang Y. Apolipoprotein E epsilon4: a possible risk factor of intracranial pressure and white matter perfusion in good-grade aneurysmal subarachnoid hemorrhage patients at early stage. Front Neurol. 2017;8:150

51. Zheng H, Chen C, Zhang J, Hu Z. Mechanism and therapy of brain edema after intracerebral hemorrhage. Cerebrovasc Dis. 2016;42:155-69.

52. Wu Y, Pang J, Peng J, Cao F, Vitek MP, Li F, Jiang Y, Sun X. An apoE-derived mimic peptide, COG1410, alleviates early brain injury via reducing apoptosis and neuroinflammation in a mouse model of subarachnoid hemorrhage. Neurosci Lett. 2016;627:92-9.

53. Hoane MR, Kaufman N, Vitek MP, McKenna SE. COG1410 improves cognitive performance and reduces cortical neuronal loss in the traumatically injured brain. J Neurotrauma. 2009;26:121-9.

54. Tukhovskaya EA, Yukin AY, Khokhlova ON, Murashev AN, Vitek MP. COG1410, a novel apolipoprotein-E mimetic, improves functional and morphological recovery in a rat model of focal brain ischemia. J Neurosci Res. 2009;87:677-82.

55. Pang J, Peng J, Matei N, Yang P, Kuai L, Wu Y, Chen L, Vitek MP, Li F, Sun X, et al. Apolipoprotein $\mathrm{E}$ exerts a whole-brain protective property by promoting M1? Microglia quiescence after experimental subarachnoid hemorrhage in mice. Transl Stroke Res. 2018;9:654-68.

56. Pan P, Zhao H, Zhang X, Li Q, Qu J, Zuo S, Yang F, Liang G, Zhang JH, Liu X, $\mathrm{He} H$, Feng $H$, Chen Y. Cyclophilin a signaling induces pericyte-associated blood-brain barrier disruption after subarachnoid hemorrhage. J Neuroinflammation. 2020;17:16.

57. Knox-Concepcion KR, Figueroa JD, Hartman RE, Li Y, Zhang L. Repression of the glucocorticoid receptor increases hypoxic-ischemic brain injury in the male neonatal rat. Int J Mol Sci. 2019;20.

\section{Publisher's Note}

Springer Nature remains neutral with regard to jurisdictional claims in published maps and institutional affiliations.

Ready to submit your research? Choose BMC and benefit from:

- fast, convenient online submission

- thorough peer review by experienced researchers in your field

- rapid publication on acceptance

- support for research data, including large and complex data types

- gold Open Access which fosters wider collaboration and increased citations

- maximum visibility for your research: over $100 \mathrm{M}$ website views per year

At $\mathrm{BMC}$, research is always in progress.

Learn more biomedcentral.com/submissions 